\title{
Why you may need a neurologist to see a comatose patient in the ICU
}

\author{
Eelco F. M. Wijdicks
}

\begin{abstract}
This commentary summarizes the value of a neurologist in the diagnosis and prognostication of coma. Evaluating coma is inherently complex, and neurologic consultation and management can be useful. We often find that management changes after a neurologic consultation.

Keywords: Comatose patient, Postcardiopulmonary resuscitation, Spontaneous eye movements, Traumatic brain injury, Prognostication
\end{abstract}

\section{Background}

Comatose patients in medical or surgical ICUs cause trepidation in the ICU team, but patients are not always evaluated by neurologists. Such consultation is probably contingent upon the following five perceptions: an evolving situation that requires neurologic expertise; something might be missed; an unusual computed tomography $(\mathrm{CT})$ scan that does not appear to explain the condition; movements that could indicate seizures with an ambiguous electroencephalogram (EEG) result; and the patient's condition looks grim but needs corroboration, with the family requesting a neurologic opinion. Neurologic consultations are most often requested when patients remain comatose after cardiopulmonary resuscitation (CPR), although in some institutions evaluation (and decisions) might be done entirely by the ICU team. Failure to awaken after surgery or after sedation has been discontinued is another typical example that triggers a request.

Evaluating coma is inherently complex, and the value of a neurologic consultation and management can be appreciated. There are also situations in which consults are highly productive; for example, cerebral fat embolization syndrome, an epidural spinal abscess in a comatose septic patient, and posterior reversible encephalopathy syndrome-all situations initially puzzling to the intensivist.

Correspondence: wijde@mayo.edu

Mayo Clinic, 200 First Street SW, Rochester, MN 55905, USA
We often find that management changes after a neurologic consultation [1]. Here are some reflections.

\section{Neurologic examination is more than a coma scale}

The Glasgow Coma Scale (GCS) is a trauma tool and has made a major difference in communication with neurosurgeons [2]. The GCS is not a neurologic examination. Important elements of neurologic examination, such as spontaneous eye movements, brainstem-reflex testing, and assessment of abnormal movements and tone, are not included, and these assessments are potentially relevant. Moreover, the reliability of the GCS is questionable [2]. Alternatively, the FOUR Score provides considerably more useful information but is also not a full neurologic examination of the comatose patient [3]. Many subtleties may swing a full assessment of coma one way or another, but initially the motor responses and brainstem reflexes can be considered together and lead to decisions on tests that narrow the probable causes of coma. If any, it is crucial to identify an embolus to the basilar artery which can be removed endovascularly (Fig. 1) [4].

\section{Confounders are found everywhere}

Evaluating coma has not become any easier. The analgosedative protocols have improved care but have not been "friendly" to neurologists [5]. Drugs linger particularly in patients treated with targeted temperature management or in those with multiorgan failure [6]. Neurologists can determine whether certain signs are more suggestive of new structural injury than drug-induced dysfunction. It is no exaggeration to say that most misjudgments of coma occur when there has been prior drug use or sedation.

\section{Not all pupils are alike}

Most literature compares clinical examination of pupillary reflex with quantitative pupillometry (often comparing nursing staff evaluations with a device [7]), but ICU studies fail to describe pupil size with pupil light reflex such as mid-position pupils or, the most important localizing 


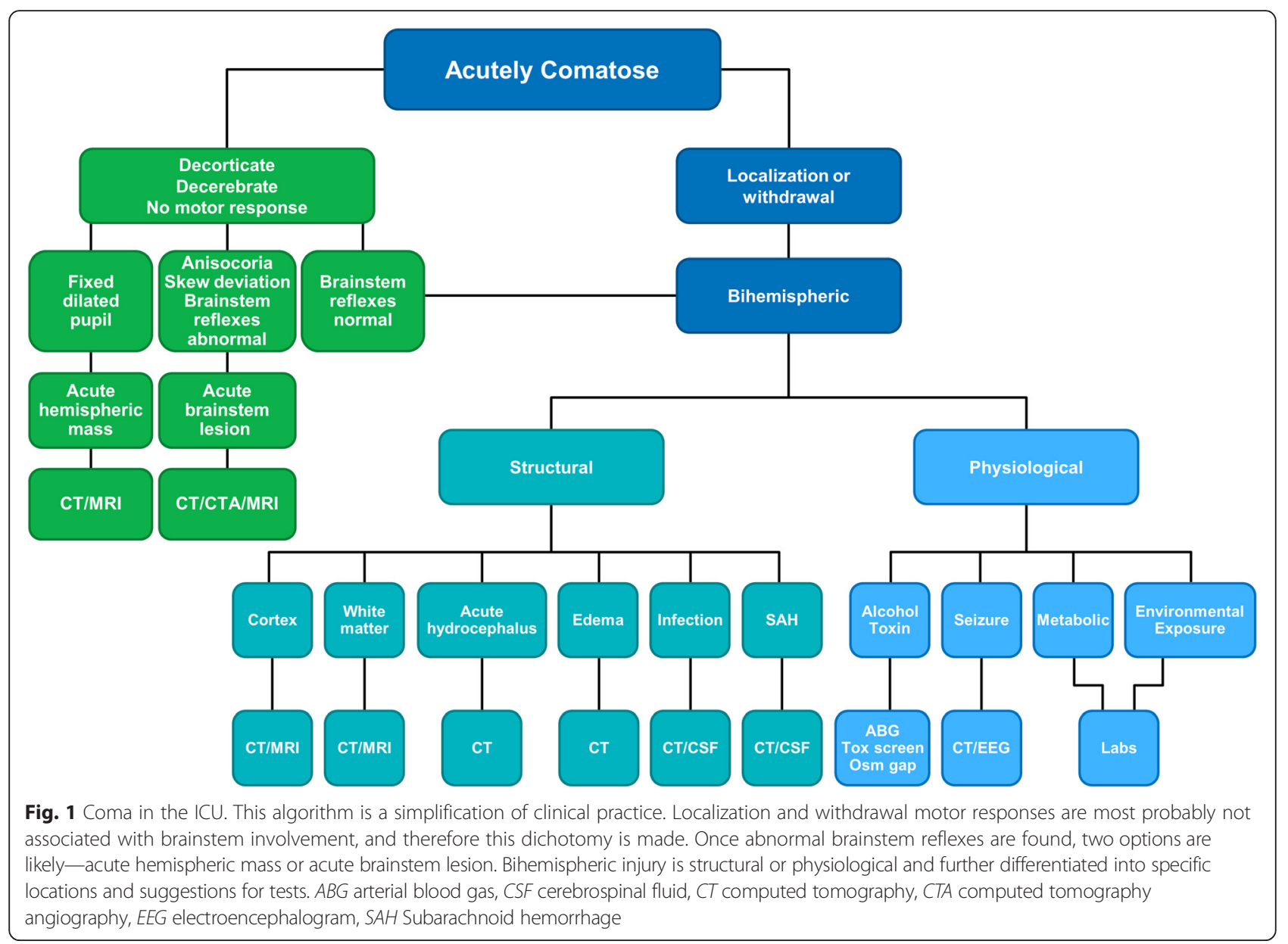

finding, anisocoria [8]. We care less about very wide or pinpoint pupils. Extremely wide pupils may or may not respond and are medication induced [9]. Pinpoint pupils often do not respond, artifactually, and are commonly opioid related.

\section{Eye movements are good indicators of brain injury}

Spontaneous eye movements are underdiagnosed and underappreciated. Many of them indicate severe structural brain injury, although they do not specifically localize, other than signal diffuse cortical injury. Important spontaneous eye movements are ping-pong eye movements, vertical nystagmus, ocular bobbing, but also vertical conjugate eye deviation. In a prospective study on post-CPR coma, specifically targeted to examine eye movements, eye deviation downward or upward appeared in nearly one in two patients. Upward deviation is often followed by downward deviation and a poor prognosticating sign $[10,11]$.

\section{Not all that seizes is a seizure}

Many critically ill patients move repeatedly, and not all shivering is myoclonus. In fact, shivering, rigor, or nonsustained clonus is often misinterpreted as myoclonus. Myoclonus status epilepticus is an unusual presentation, often seen after prolonged CPR or exsanguination, and is vigorous and forceful, with jerks involving all four limbs and significant facial distortions, all in association with upward eye jerks.

\section{Could we practice with fewer EEGs"?}

It is not common to diagnose status epilepticus in an acutely comatose patient without any evidence of a prior seizure, history of seizures or major predispostion for seizures. The circumstances surrounding critical illness could make patients more vulnerable to seizures; however, while few patients in the ICU have seizures, many more undergo an EEG. Moreover the interpretation of an abnormal EEG in these patients remains far from accurate. If the published studies are true-and I think they are-and even if nonconvulsive status epilepticus is found management of nonconvulsive status epilepticus may not necessarily lead to better outcome if associated with irreversible cortical injury. EEG's may indicate a poor prognosis but only with burst-suppression or flat background in an undrugged patient but such has been known 
by generations of neurologists. An EEG in a comatose patient should never be used to make important decisions on care.

\section{Toxic metabolic encephalopathies are so yesterday} Elevated ammonia or blood urea nitrogen values seldom correlate with neurologic examination. Even if we think a correlation exists, nephrologists and hepatologists often deny it. For nearly half a century, patients who failed to awaken, were stuporous, or who were not clearly agitated were labeled as having a "toxic metabolic encephalopathy." Some may be delirious. Some may have posterior reversible encephalopathy syndrome, cefepime toxicity, or metabolize drugs slowly. In many patients with decreased alertness we simply do not know the cause and often symptoms resolve $[12,13]$.

\section{Neurologists know when to call a neurosurgeon or neurointerventionalist}

Traumatic brain injury may require neurosurgical intervention, and this may not be clear on admission. Contusions and subdural hematomas may have delayed presentations [14]. Ischemic strokes do occur in cardiovascular surgical ICUs. With some of these patients, the onset time is tentatively known, and a CTA and CT perfusion can determine whether endovascular clot retrieval is warranted. Neurologists may also know when not to call a neurosurgeon (i.e. no indication for surgery).

\section{Finally}

We may bring closure when it comes to prognostication. We also-more frequently-say we do not know what the future holds. This part of consultative neurology is difficult and not for everyone. Assertively clarifying the reality to the patient's family easily takes a toll both on neurologists and families witnessing their loved one's neurologic state. We must avoid a poor outcome due to our self-fulfilling misjudgment or, worse, our coercion. We also must avoid analysis paralysis or creating false hope. Often, with decades of experiences, it is not so much probabilistic logic but more we know when we know.

\footnotetext{
Abbreviations

CPR, cardiopulmonary resuscitation; $C T$, computed tomography; CTA, computed tomography angiography; EEG, electroencephalogram; GCS, Glasgow Coma Scale
}

Funding

No grant funding supported the preparation of this article.

\section{Authors' information}

EFMW is Professor of Neurology and Chair of the Division of Critical Care Neurology at Mayo Clinic Hospital Saint Mary's Campus.

Competing interests

The author declares that he has no competing interests.
Published online: 20 June 2016

\section{References}

1. Mittal MK, Kashyap R, Herasevich V, Rabinstein AA, Wijdicks EF. Do patients in a medical or surgical ICU benefit from a neurologic consultation? Int J Neurosci. 2015;125:512-20.

2. Reith FC, Van den Brande R, Synnot A, Gruen R, Maas Al. The reliability of the Glasgow Coma Scale: a systematic review. Intensive Care Med. 2016;42:3-15.

3. Wijdicks EF, Bamlet WR, Maramattom BV, Manno EM, McClelland RL. Validation of a new coma scale: the FOUR score. Ann Neurol. 2005:58:585-93.

4. Wijdicks EFM. The comatose patient. 2nd ed. New York: Oxford University Press; 2014.

5. Devabhakthuni S, Armahizer MJ, Dasta JF, Kane-Gill SL. Analgosedation: a paradigm shift in intensive care unit sedation practice. Ann Pharmacother. 2012:46:530-40.

6. Samaniego EA, Mlynash M, Caulfield AF, Eyngorn I, Wijman CA. Sedation confounds outcome prediction in cardiac arrest survivors treated with hypothermia. Neurocrit Care. 2011;15:113-9.

7. Zafar SF, Suarez Jl. Automated pupillometer for monitoring the critically ill patient: a critical appraisal. J Crit Care. 2014;29:599-603.

8. Burns JD, Schiefer TK, Wijdicks EF. Large and small: a telltale sign of acute pontomesencephalic injury. Neurology. 2009;72:1707.

9. Braksick SA, Wijdicks EF. Moisture and mydriasis. Pract Neurol. 2014;14:187-8.

10. Johkura K, Komiyama A, Kuroiwa Y. Vertical conjugate eye deviation in postresuscitation coma. Ann Neurol. 2004:56:878-81.

11. Johkura K, Komiyama A, Kuroriwa Y. Sustained downgaze in coma after cardiac arrest. J Neurol Neurosurg Psychiatry. 2001;71:278-9.

12. Fugate JE, Kalimullah EA, Hocker SE, Clark SL, Wijdicks EF, Rabinstein AA. Cefepime neurotoxicity in the intensive care unit: a cause of severe, underappreciated encephalopathy. Crit Care. 2013;17:R264.

13. Fugate $J E$, Rabinstein $A A$. Posterior reversible encephalopathy syndrome: clinical and radiological manifestations, pathophysiology, and outstanding questions. Lancet Neurol. 2015;14:914-25.

14. Servadei F, Nanni A, Nasi MT, Zappi D, Vergoni G, Giuliani G, et al. Evolving brain lesions in the first 12 hours after head injury: analysis of 37 comatose patients. Neurosurgery. 1995;37:899-906. discussion 906-7. 